\title{
Seroepidemiology and Risk Factors Of Blood-Borne Virus Infections Among Drug Users in Uppsala County, Sweden
}

\author{
Staffan P.E. Sylvan ${ }^{*}, 1$, Johan Hedlund ${ }^{1}$, Gunilla Ohlén ${ }^{1}$, Eva Lundell ${ }^{2}$, Kare Bondeson ${ }^{3}$ and the \\ Uppsala County Working Group Against Drug Dependency
}

\author{
${ }^{I}$ The Department of Communicable Disease Control and Prevention, Uppsala County Council and Departments of \\ ${ }^{2}$ Infectious Diseases and ${ }^{3}$ Virology, Department of Medical Sciences, Uppsala University Hospital, Uppsala, Sweden
}

\begin{abstract}
The prevalence, risk factors, and prevention opportunities of hepatitis A, B, C and HIV infection was studied in injecting drug users (IDUs) in comparison with non-injecting drug users (n-IDUs) in Uppsala County, Sweden.

The seroprevalence among IDUs were $0.7 \%$ for HIV, 19\% for HAV, $26 \%$ for HBV and $63 \%$ for HCV. For hepatitis C, the seroprevalence was directly related to the number of years of injections. No cases of HIV were found among the nIDUs and the seroprevalence rate was significantly lower for $\mathrm{HBV}$ and $\mathrm{HCV}, 6$ and $2 \%$, respectively. In contrast, the antiHAV antibody seroprevalence was not significantly different between $\mathrm{n}$-IDUs and IDUs ( $27 \% v s 19 \%$, $\mathrm{p}<\mathrm{ns})$. There was no difference in vaccination uptake among IDUs compared with n-IDUs.

Hepatitis A and B vaccination should be considered as one component of a comprehensive programme including counselling, support and education of blood-borne infections associated with drug use.
\end{abstract}

\section{INTRODUCTION}

Blood-borne viruses, such as hepatitis $\mathrm{A}, \mathrm{B}$ and $\mathrm{C}(\mathrm{HAV}$, $\mathrm{HBV}, \mathrm{HCV}$ ) and the human immunodeficiency virus (HIV) are common among illicit drug users and their sexual partners mainly because of sharing of injection equipment, having unprotected sexual behaviour with persons belonging to high-risk groups and living in unsanitary living conditions [1-3]. In non-endemic countries (e.g., Sweden) both large and small outbreaks of hepatitis A and B infection among injecting drug users (IDUs) and their sexual partners have occurred $[4,5]$. In fact, sero-epidemiological studies suggest that in comparison with the general population, there is a high prevalence of chronic HCV infection among IDUs [6, 7]. The prevention of hepatitis $B$ and $C$ virus infections is also of major public health concern because infected individuals carry a substantial risk of chronic liver disease of 2 to $5 \%$ for HBV and of 75 to $85 \%$ for HCV $[8,9]$. Furthermore, individuals infected with HBV, and to a lesser degree those with $\mathrm{HCV}$ infection, may transmit the virus to their sexual partners and in the case of females to their offspring $[10,11]$.

It has been suggested that $\mathrm{HAV}$ and $\mathrm{HBV}$ vaccination programmes and syringe/needle exchange programmes (NEP), especially in high-risk groups, could limit the spread of both infections and curtail the spread of HIV. Legal access to needles and NEP as part of a strategy to prevent the transmission of HIV has been heavily debated. Advocates claim that these programmes create venues for contact between the IDUs and the health care system, where harm-

*Address correspondence to this author at the Department of Communicable Disease Control and Prevention, Uppsala County Council, Dag Hammarskjolds vag 17, SE-751-85 Uppsala, Sweden; Tel: 0461861192 20;

Fax: 046185529 01; E-mail: staffan.sylvan@lul.se reducing measures such as HIV and hepatitis counselling and vaccination can be implemented. Prison, remand centres, homeless shelters and street outreach are also recognised as being possible venues for contact between drug users and the health care system, where effective harm-reduction strategies aimed in preventing the spread of blood-borne viruses could benefit this high-risk population $[6,12,13]$.

The objective of this study was to analyse, in the absence of a legal NEP, the feasibility of a voluntary preventive programme comprising HIV as well as hepatitis counselling and testing in association with a vaccination programme against hepatitis $\mathrm{A}$ and $\mathrm{B}$ among injecting and non-injecting drug users (n-IDUs) in Uppsala County, Sweden.

\section{MATERIALS AND METHODOLOGY}

In Sweden, the County medical Officer (CMO) is obliged by the Swedish communicable diseases Act to implement preventive measures to reduce the spread of communicable diseases among those groups of individuals that are at particularly high risk for infection. One such group is illicit drug users. Written informed consent of the study population was not necessary because this study did not modify the existing diagnosis or the therapeutic strategy. Between April 2003 and December 2006 all drug users older than 15 years were offered to participate and voluntarily recruited from five recruitment settings. The participants received no monetary incentive but were offered vaccination against hepatitis A and $\mathrm{B}$ free of charge. The response rate among eligible clients of recruitment sites during the study period was $30 \%$ at the Remand prison and $25 \%$ at the correctional facility. 155 participants were recruited from detained individuals at the Remand Prison in Uppsala, 67 were recruited among inmates at the local correctional facility in Åby, Uppsala County, 34 were recruited among patients with drug use that were referred for medical evaluation to the Department of Infectious 
Diseases at the Uppsala University Hospital, Uppsala, 26 were recruited at the medical centres for homeless people in the two cities Uppsala and Enköping, and 11 individuals were recruited at the Uppsala social services administration office. 51 participants denied using drugs or had incomplete information and were therefore excluded from the final analysis. Thus, the final sample consisted of 243 participants (217 males, 26 females).

Participants completed an interviewer-administrated questionnaire that assessed the type, frequency and duration of their drug use and sharing of drug equipment. In addition, the participants were asked about their sexual behaviour, condom use and whether the partner was a drug user and had a blood-borne virus infection. The questionnaire was administered by a specially trained nurse who also performed the venipuncture. After completion of the interview, participants received information leaflets, underwent counselling for hepatitis A, B, C, and HIV infection and had a blood specimen drawn for serological testing. Blood was drawn for testing from 145 IDUs and 98 who denied personal IV drug use and by whom 3 were sexual partners of drug injectors. All of the participants denied homosexual contacts.

The serum samples were tested for antibodies to HAV (anti-HAV Total, Vitros, Ortho-Clinical Diagnostics, Raritan, NJ), hepatitis B surface antigen (HBsAg, Vitros, OrthoClinical Diagnostics, Raritan, NJ), for antibodies to the hepatitis B core antigen (anti-HBc, Vitros, Ortho-Clinical Diagnostics, Raritan, NJ), hepatitis C (anti-HCV, Vitros, OrthoClinical Diagnostics, Raritan, NJ) and HIV (anti-HIV, Vitros, Ortho-Clinical Diagnostics, Raritan, NJ or Axsym HIV $\mathrm{Ag} / \mathrm{Ab}$ Combo, Abbott diagnostics, Abbott Park, IL). Strip immunoblot assays (SIA) was used as confirmatory tests for anti-HCV (RIBA HCV 3.0 SIA, Chiron Corporation, Emeriville, CA) and anti-HIV (RIBA HIV-1/HIV-2 SIA, Chiron Corporation, Emeriville, CA).

All participants were offered vaccination against hepatitis $A$ and $B$ free. We used the super-accelerated programme with injections at 0,7 , and 21 days; a booster was administered at the 12-month stage. A person who stays in detention or incarcerated in prison for less than the time it takes to administer three doses will not complete the vaccination programme. Ensuring that these drug users complete the full course of injections is an ongoing problem.

\section{STATISTICAL METHODS}

We used Pearson's chi-square test and Fischer 's exact test to compare proportions in independent groups of categorical data. The chi-square test for trend was performed to identify linear trends.

\section{RESULTS}

Of the 243 participants, $145(60 \%)$ reported previous or ongoing injection use. The sample was heterogeneous regarding ethnicity. Never injectors were more likely than injectors to be born outside Sweden. Table 1 shows the basic sociodemographic and behavioural characteristics. The median age was 33.4 years (range 16-58 years) for injectors and 30.8 years (range 15-63 years) for non-injectors respectively. Of the injectors, $72 \%$ had injected with syringes already used by another person ("syringe sharing"): 35 (24\%) of the participants used heroin and $74 \%$ amphetamine. Cannabis was the most common drug used among non-injectors, being reported by 58 individuals (59\%).

Table 1. Sample Characteristics and prevalence of HIV, HAV, HBC and HCV Infection Among Drug Users in Uppsala County, Sweden $(n=243)$

\begin{tabular}{|c|c|c|c|c|c|}
\hline & \multicolumn{2}{|c|}{ Injectors } & \multicolumn{2}{|c|}{ Non-Injectors } & \multirow{3}{*}{ P-Value * } \\
\hline & & $(\%)$ & $\mathbf{N}$ & $(\%)$ & \\
\hline & 145 & $(60)$ & 98 & (40) & \\
\hline $\mathrm{Age}<30$ & 63 & (44) & 53 & (54) & ns \\
\hline$>30$ & 82 & $(56)$ & 45 & (46) & ns \\
\hline \multicolumn{6}{|l|}{ Ethnicity } \\
\hline Swedish born & 125 & (86) & 66 & (67) & $<0.001$ \\
\hline Foreign born & 20 & (14) & 32 & (33) & $<0.001$ \\
\hline \multicolumn{6}{|l|}{ Gender } \\
\hline female & 17 & (12) & 9 & (9) & ns \\
\hline male & 128 & (88) & 89 & (91) & ns \\
\hline \multicolumn{6}{|l|}{$\begin{array}{l}\text { Injection with } \\
\text { shared syringes }\end{array}$} \\
\hline No & 41 & $(28)$ & 0 & & \\
\hline Yes & 104 & $(72)$ & 0 & & \\
\hline HIV infection & 1 & $(0.7)$ & 0 & (0) & \\
\hline HAV infection & 28 & (19) & 26 & (27) & ns \\
\hline HBV infection & 38 & $(26)$ & 6 & (6) & $<0.001$ \\
\hline HCV infection & 91 & $(63)$ & 2 & (2) & $<0.001$ \\
\hline \multicolumn{6}{|l|}{ DRUGS } \\
\hline amphetamine & 108 & (74) & 22 & (22) & $<0.001$ \\
\hline heroin & 35 & (24) & 2 & (2) & $<0.001$ \\
\hline cocaine & 16 & (11) & 8 & (8) & ns \\
\hline hash/cannabis & 45 & (31) & 58 & (59) & $<0.001$ \\
\hline \multicolumn{6}{|l|}{ Vaccination } \\
\hline 1 injection & 119 & (82) & 80 & (81) & ns \\
\hline 2 injection & 45 & (31) & 37 & (38) & ns \\
\hline 3 injection & 32 & (22) & 30 & (31) & ns \\
\hline
\end{tabular}

The seroprevalence rates among IDUs were $0.7 \%$ for $\mathrm{HIV}, 19 \%$ for HAV, $26 \%$ for HBV, and $63 \%$ for HCV. 14 (10\%) IDUs were HBsAg-positive. IDUs who injected amphetamine were significantly more likely to be infected with $\mathrm{HCV}$ and $\mathrm{HBV}$ compared with those who injected heroin ( $72 \%$ vs $54 \%, \mathrm{p}<0.05$ and $32 \%$ vs $11 \%, \mathrm{p}<0.01$, respectively; Table 2). In $30 \%$ (44 individuals) of the IDUs none of the seromarkers was seen for any of the four viral infections, whereas $55 \%(80)$ were seropositive for one seromarker, $24 \%$ (35) for two and $8 \%$ (12) for three. 
Table 2. Prevalence of HCV and HBV infections in Relation to Drug Use and Needle Sharing

\begin{tabular}{|c|c|c|c|c|c|c|}
\hline & N & HCV + & HBV + & Shared Syringes & Shared Syringes HCV + HBV + & Years of Injection \\
\hline \hline Amphetamine & 108 & $7872 \%$ & $3432 \%$ & $7771 \%$ & $5571 \% 2229 \%$ & 15.2 \\
\hline Heroin & 35 & $1954 \%$ & $411 \%$ & $2469 \%$ & $1250 \% 417 \%$ & 7.7 \\
\hline & & $\mathrm{p}^{*}<0.05$ & $\mathrm{p}<0.01$ & $\mathrm{p}=\mathrm{ns}$ & $\mathrm{p}<0.05 \mathrm{p}=\mathrm{ns}$ & \\
\hline
\end{tabular}

* Chi-squared test.

$\mathrm{ns}=$ not significant.

None of the injectors had evidence of hepatitis B immunization (anti-HBs alone).

For hepatitis $\mathrm{C}$, the seroprevalence was directly related to the number of years of injections (Fig. 1). HCV antibody prevalence was 38\% among participants with less than one year of injection, reaching $93 \%$ among IDUs who had injected for 10 years or more. No cases of HIV were found among the non-injectors and the seroprevalence rate was significantly lower in non-injectors for HBV and HCV compared with the injectors ( 6 and $2 \%$ respectively). In contrast, the anti-HAV antibody seroprevalence was not significantly different between the non-injectors and injectors $(27 \%$ vs $19 \%, \mathrm{p}<\mathrm{ns})$.

The majority of the IDUs (194 or 80\%) reported heterosexual activity in the year prior to committal. 32 of those individuals $(16 \%)$ of those who had heterosexual intercourse reported using condoms (always or sometimes), whereas $43(22 \%)$ claimed that they never used condoms and 119 (61\%) did not respond to the question. The mean number of sexual partners during the past 12 months reported by heroin injectors users was 2.6 and 2.3 for amphetamine injectors. For non-injectors, the mean number of sexual partners was 2.4. The number of sex partners among those with markers for HBV and HCV was 1.8 and 1.7 , respectively, whereas those without these markers had 2.4 sexual partners during the previous year.

Of the 243 participants, $62(26 \%)$ completed a three-dose course of hepatitis A and B vaccination, 82 (34\%) received two doses and $199(82 \%)$ received one dose of the bivalent vaccine. There was no difference in vaccination uptake among IDUs compared with non-IDUs. However, adherence to the vaccination schedule was not always maintained. The median time between the first and the second injection was 19 days (range 6-244 days) instead of the intended 7 days and the median time for the third injection was 34 days (range 12-434 days) instead of 21 days.

\section{DISCUSSION}

Our data indicate that in Uppsala, a Swedish city without a syringes/needle exchange programme, more than $60 \%$ of IDUs have serological evidence of hepatitis C, but only $0.7 \%$ are HIV positive. Low prevalence of HIV and high rates of $\mathrm{HCV}$ infection among IDUs has been described previously from different geographical areas [14-18].

The low prevalence of HIV as compared with HCV among IDUs in the Uppsala area (5/100.000 inhabitants vs 455/100.000 inhabitants) may be a plausible explanation for this difference. Moreover, IDUs in Sweden are encouraged to participate in HIV counselling and voluntary testing for HIV. The IDUs who know that they are HIV seropositive are much less likely to pass on used needles and syringes compared with IDUs who know that they are seronegative, which could reduce the risk of further transmission of the virus $[19,20]$. We have previously shown that HIV seropositive individuals with the intellectual and psychiatric capacity to comprehend the serious nature of HIV infection and its modes of transmission can successfully modify risk behaviour after being diagnosed with HIV [21]. Recently a comparison of HIV prevention strategies in Scandinavia suggested that a high level of HIV counselling and testing can be more effective in confining HIV at a low level than legal access to needles and syringes/NEPs [22].

The overall seroprevalence for HCV among injectors was greater than that for HBV. A higher prevalence of $\mathrm{HCV}$ infection is consistent with observations from almost all populations of IDUs $[6,14,15,17,18]$. It has been shown that the number of infectious carriers in the drug-using community is different for each infection at a given time point, which influences the transmissibility of the virus infection [23]. In this study, HCV and HBV infections were significantly associated with am-

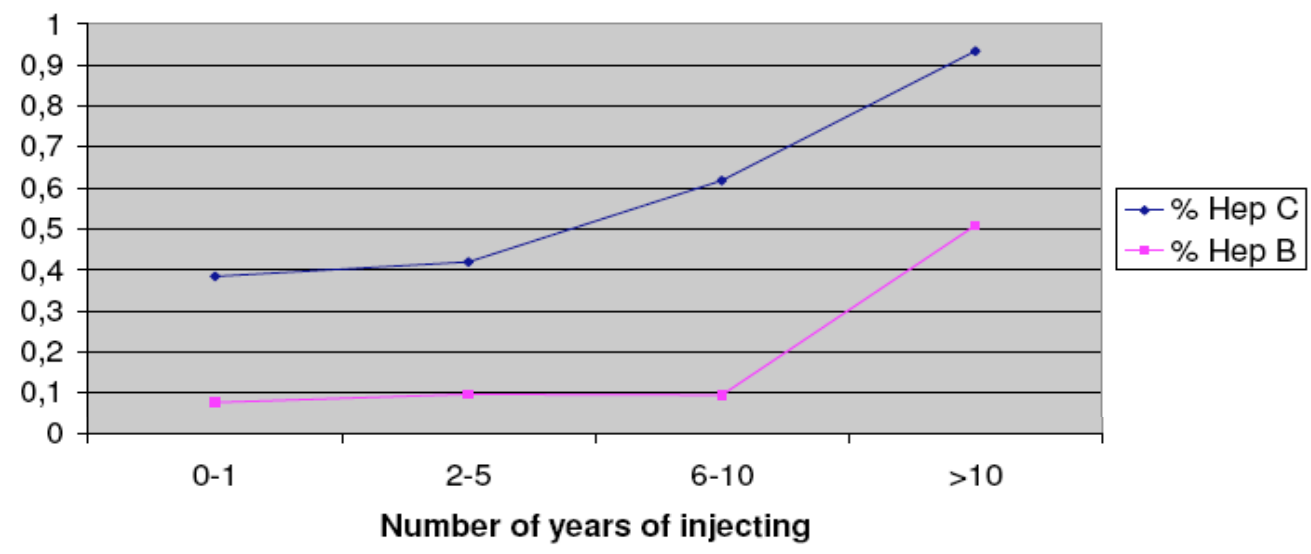

Fig. (1). Proportion of injecting drug users infected with hepatitis $\mathrm{C}$ virus (HCV) and hepatitis B virus (HBV) as a function of number of years of injecting. 
phetamine injection. This finding could be explained by the fact that the amphetamine injectors had been injectors for a longer period of time compared with the heroin injectors and thus had more time to be exposed for the infection. Moreover, he amphetamine injectors with hepatitis $\mathrm{C}$ also admitted to more frequent needle sharing practices compared to the $\mathrm{HCV}$ infected heroin injectors.

Although studies of exposed healthcare workers have shown that the transmissibility of $\mathrm{HCV}$ is substantially lower than that for HBV [24]. The higher levels of chronic carriage among IDUs with HCV (63\% in our study) leads to more effective spread of the virus among IDUs compared with HBV, $(10 \%$ carriers) and have contributed to this finding.

We found that duration of injecting is highly associated with HCV seroprevalence. It has been estimated that the weightedaverage time to seroconversion after beginning to inject was estimated to be 3.4 years [25]. Therefore, it seems reasonable to assume that among IDUs, sufficient time exists between initiation of injection drug use and subsequent $\mathrm{HCV}$ infection to target them for prevention. Despite its high prevalence among IDUs, many individuals who inject drugs do not know their HCV serostatus [26] or, if they have been informed of having a nonA-, nonB- related liver disease diagnosed before 1992, do not appreciate the seriousness of their infection. Many IDUs displayed confusion about transmission risks for hepatitis $\mathrm{C}$ and what a positive HCV diagnosis meant for their own health and their ability to infect others [27] Thus, they will not seek medical care until their health is significantly compromised. Moreover, treatment options will be severely restricted and they may have unknowingly transmitted the virus to others by direct sharing of needles and syringes or indirect by other injection paraphernalia [28]. Therefore, it is of importance that drug treatment programs fill this HCV education service gap among drug users by providing $\mathrm{HCV}$ education to their patients.

Hepatitis B vaccination has been recommended for IDUs in Sweden since 1991 (ref SOSFS 1991:2), but coverage remains low and hepatitis B outbreaks among IDUs and their sexual partners continue to occur [4]. This observation is in accordance with the absence of HBV-vaccinated IDUs of our study population.

The seroprevalence rates for blood-borne viral infections in our population of IDUs are lower compared with IDUs attending general practitioners in Belgian [16], prisoners in a median security prison in Denmark [29], prisoners in the Republic of Ireland [17], and Germany [30], participants recruited by multisite sampling at different agencies for IDU in Georgia [18] or clients attending methadone treatment clinics in New Zealand [31] and Switzerland [32], but slightly higher compared with new drug injectors in New York [33], suggesting that our venues of contact reach IDUs at a relatively earlier stage of their drug-using career. The data underline the feasibility of our efforts to find ways of early interventions among new IDUs that combine mass screening for infection with blood-borne pathogens, information campaigns and HAV and HBV vaccination programmes, along with interventions targeted at high-risk subpopulations of new IDUs to prevent HAV, HBV and HCV epidemics as well as potential HIV epidemics.

The HCV seroprevalence among individuals who use drugs but do not inject was considerably lower than that among IDUs. In this study the seroprevalence of HCV in non-injectors was $2 \%$, which is higher than the $0.37 \%$ observed in a middle-aged Swedish general urban population [34]. Compared with sero- prevalence data obtained from n-IDUs in other studies, the prevalence of HCV infection in our group of non-injectors in Uppsala County is much lower [35]. One explanation for our finding is that the majority of our sample included users of drugs (e.g., smoking cannabis and marijuana) or oral administration of drugs (e.g., amphetamine and club drugs such as ecstasy), which should not lead to blood-to-blood contact and subsequent HCV transmission [35]. Our finding could also be attributed to the fact that non-injectors in this study tended to be younger than n-IDUs in prior studies. Evidence of the link between younger age and HCV prevalence among n-IDUs has been compiled in several studies $[36,37]$. The high acceptance rate to commence vaccination against hepatitis $\mathrm{A}$ and $\mathrm{B}$ in this cohort of drug users is similar to other hepatitis vaccination studies in Europe [38]. However, vaccine coverage with three injections tended to be low. Even if the vaccination programme was incompletely implemented it could nevertheless have an impact on the extent and case-fatality rate of an acute hepatitis A or B outbreak in which transmission is limited to this highrisk group that often is co-infected with chronic hepatitis $\mathrm{C}$.

In interpreting the results of this study several limitations should be considered. First, this study population does not represent all IDUs and n-IDUs in Uppsala County. It represents only those who were approached at the contact sites and who were willing to participate. We can not exclude the possibility that we recruited biased samples of IDUs and n-IDUs; however, we attempted to minimise this possibility by recruiting from various sites within the community. Still, our sample was not randomly selected and findings may not be generalised to the larger drug user community. A second limitation is that the seroprevalence estimate may be inaccurately reported. Those who are infected and know that they are infected may have been less likely to agree to be tested which could result in an underestimate of the true prevalence rate.

\section{CONCLUSION}

Because injection drug use seems to be a highly efficient mode of transmitting blood-borne infections, particular efforts should be directed to toward helping young IDUs to stop injecting drugs. Hepatitis A and B vaccination should be considered as one component of a comprehensive programme including counselling, support and education of blood-borne infections associated with drug use.

\section{ACKNOWLEDGEMENTS}

We would like to thank the participants of the Uppsala County Council Working group against drug dependency (Sylvia Augustini, Margaretha Lhådö and Knut Bodin at Uppsala County Council, Kenneth Olsson and Henrik Thelander at Uppsala Police Authority, Åsa Carlsson at Uppsala Social Services Administration and Birgitta Nytell at Uppsala Prison and Probation administration).

This study was partly financed by The Swedish Institute of Public Health and The National Board of Health and Welfare, Stockholm, Sweden.

\section{REFERENCES}

[1] Lappalainen, M.; Chen, R.W.; Manulla, L.; von Bonsdorff, C-H.; Plyusnin, A.; Vaheri, A. Molecular epidemiology of viral pathogens and tracing of transmission routes: hepatitis-, calici- and hantaviruses. $J$. Clin. Virol., 2001, 21, 177.

[2] Long, J.; Allwright, S.; Barry, J.; Reynolds, S.R.; Thornton, L.; Bradley, F.; Parry, J.V. Prevalence of antibodies to hepatitis B, hepatitis C, and 
HIV and risk factors in entrants to Irish prisons: a national cross sectional survey. BMJ, 2001, 323, 1209.

[3] Alvarado-Esquivel, C.; Sablon, E.; Martinez-Garcia, S.; EstradaMartinez, S. Hepatitis virus and HIV infections in inmates of a state correctional facility in Mexico. Epidemiol. Infect., 2005, 133, 679.

[4] Christenson, B. Epidemiology of hepatitis B in Sweden. J. Infect., 1987, $15,269$.

[5] Eitrem, R.; Norder, H.; Sundqvist, L.; Magnius, L. Results of the hepatitis A epidemic in Blekinge. Transmission links surveyed with the help of sequence analysis of viral RNA. Lakartidningen, 2002, 38, 3682 (Article in Swedish).

[6] Månsson, A.S.; Moestrup, T.; Nordenfeldt, E.; Widell, A. Continued transmission of hepatitis $\mathrm{B}$ and $\mathrm{C}$ viruses, but no transmission of human immunodeficiency virus among intravenous drug users participating in a syringe/needle exchange program. Scand. J. Infect. Dis., 2000, 32, 253.

[7] Struve, J.; Aronsson, B.; Frenning, B.; Forsgren, M.; Weiland, O. Prevalence of antibodies against hepatitis $\mathrm{C}$ virus infection among health care workers in Stockholm. Scand. J. Gastroenterol., 1994, 29, 360 .

[8] Hoofnagle, J.H.; Doo, E.; Liang T.J.; Fleischer, R.; Lok, A.S. Management of hepatitis B: summary of a clinical research workshop. Hepatology, 2007, 45, 1056.

[9] Hoofnagle, J.H. Course and outcome of hepatitis C. Hepatology, 2002, $36, \mathrm{~S} 21$.

[10] Menendez, C.; Sanchez-Tapias, J.M.; Kahigwa, E.; Mshinda, H.; Costa, J.; Vidal, J.; Acosta, C.; Lopez-Labrador, X.; Olmedo, E.; Navia, M.; Tanner, M.; Rodes, J.; Alonso, P.L. Prevalence and mother-to-infant transmission of hepatitis viruses B, C, and E in Southern Tanzania. $J$. Med. Virol., 1999, 58, 215.

[11] Dal Molin, G.; Dágaro, P.; Ansaldi, F.; Ciana, G.; Fertz, C.; Alberico, S.; Campello, C. Mother-to-infant transmission of hepatitis $\mathrm{C}$ virus: rate of infection and assessment of viral load and IgM anti-HCV as risk factors. J. Med. Virol., 2002, 67,137.

[12] United Nations. Preventing the transmission of HIV among drug abusers: a position paper of the United Nations System. Geneva: United Nations, 2000.

[13] World Health Organization. Status paper on prisons, drugs, and harm reduction. World Health Organization Europe, May 2005.

[14] Des Jarlais, D.C.; Diaz, T.; Perlis, T.; Vlahov, D.; Maslow, C.;Latka, M.; Rockwell, R.; Edwards, V.; Friedman, S.R.; Monterroso, E.; Williams, I.; Garfein, R.S. Variability in the incidence of human immunodeficiency virus, hepatitis B virus, and hepatitis $\mathrm{C}$ virus infection among young injecting drug users in New York City. Am. J. Epidemiol., 2003, 157, 467 .

[15] Crofts, N.; Hopper, J.L.; Milner, R.; Breschkin, A.M.; Bowden, D.S.; Locarnini, S.A. Blood-borne virus infections among Australian injecting drug users: implications for spread of HIV. Eur. J. Epidemiol., 1994, 10, 687 .

[16] Denis, B.; Dedobbeleer, M.; Collet, T.; Petit, J.; Jamoulle, M.; Hayani, A.; Brenard, R. High prevalence of hepatitis $\mathrm{C}$ virus infection in Belgian intravenous drug users and potential role of the "cotton-filter" in transmission: the GEMT Study. Acta Gastroenterol. Belg., 2000, 63, 147.

[17] Allwright, S.; Bradley, F.; Long, J.; Barry, J.; Thornton, L.; Parry, J.V. Prevalence of antibodies to hepatitis $\mathrm{B}$, hepatitis $\mathrm{C}$, and HIV and risk factors in Irish prisoners: results of a national cross sectional survey. $B M J, 2000,321,78$.

[18] Shapatava, E.; Nelson, K.E.; Tsertsvadze, T.; del Rio, C. Risk behaviors and HIV, hepatitis $\mathrm{B}$, and hepatitis $\mathrm{C}$ seroprevalence among injection drug users in Georgia. Drug Alcohol Depend., 2006, 82, S35.

[19] des Jarlais, D.C.; Friedmann, P.; Hagan, H.; Friedman, S.R. The protective effect of AIDS-related behavioral change among injection drug users: a cross-national study. WHO Multi-Centre Study of AIDS and Injecting Drug Use. Am. J. Public Health., 1996, 86, 1780.

[20] Nicolosi, A.; Molinari, S.; Musicco, M.; Saracco, A.; Ziliani, N.; Lazzarin, A. Positive modification of injecting behavior among intravenous heroin users from Milan and northern Italy 1987-1989. NISDA Study. Br. J. Addict., 1991, 86,91.

[21] Sylvan, S.; Gustavsson, M.; Christenson, B. Evaluation of the law of communicable disease control: compulsory isolation can reduce the high-risk behavior of HIV-positive individuals. Lakartidningen, 1999, 96, 3244 .

[22] Amundsen, E.J.; Eskild, A.; Stigum, H.; Smith, E.; Aalen, O.O. Legal access to needles and syringes/needle exchange programmes versus HIV counselling and testing to prevent transmission of HIV among intravenous drug users: a comparative study of Denmark, Norway and Sweden. Eur. J. Public Health, 2003, 13, 252.

[23] Garfein, R.S.; Vlahov, D.; Galai, N.; Doherty, M.C.; Nelson, K.E. Viral infections in short-term injection drug users: the prevalence of the hepatitis C, hepatitis B, human immunodeficiency, and human $\mathrm{T}$ lymphotropic viruses. Am. J. Public Health, 1996, 86, 655.

[24] Alter, M. The detection, transmission, and outcome of hepatitis $\mathrm{C}$ virus infection. Infect. Agents Dis., 1993, 2, 155.

[25] Hagan, H.; Thiede, H.; Des Jarlais, D.C. Hepatitis C virus infection among injection drug users: survival analysis of time to seroconversion. Epidemiology, 2004, 15, 543.

[26] Danis, K.; Doherty, L.; McCartney, M.; McCarrol, J.; Kennedy, H. Hepatitis and HIV in Northern Ireland prisons: a cross-sectional study. Euro Surveill., 2007, 12, 9.

[27] Strauss, S.M.; Astone-Twerell, J.; Munoz-Plaza, C.; Des Jarlais, D.C.; Gwadz, M.; Hagan, H.; Osborne, A.; Rosenblum, A. Drug treatment program patients' hepatitis $\mathrm{C}$ virus (HCV) education needs and their use of available HCV education services. BMC Health Serv. Res., 2007, 7, 39.

[28] Rhodes, T.; Davis, M.; Judd, A. Hepatitis C and its risk management among drug injectors in London: renewing harm reduction in the context of uncertainty. Addiction, 2004, 99, 621

[29] Christensen, P.B.; Krarup, H.B.; Niesters, H.G.; Norder, H.; Georgsen, J. Prevalence and incidence of blood borne viral infections among Danish prisoners. Eur. J. Epidemiol., 2000, 16, 1043.

[30] Stark, K.; Herrmann, U.; Ehrhardt, S.; Bienzle, U. A syringe exchange programme in prison as prevention strategy against HIV infection and hepatitis B and C in Berlin, Germany. Epidemiol. Infect., 2006, 134, 814.

[31] Chetwynd, J.; Brunton, C.; Blank, M.; Plumridge, E.; Baldwin, D. Hepatitis $\mathrm{C}$ seroprevalence amongst injecting drug users attending a methadone programme. $N Z$ Med J., 1995, 108, 364.

[32] Broers, B.; Junet, C.; Bourquin, M.; Deglon, J-J. ; Perrin, L.; Hirschel, B. Prevalence and incidence rate of HIV, hepatitis B and C among drug users on methadone maintenance treatment in Geneva between 1988 and 1995. AIDS, 1998, 12, 2059

[33] Neaigus, A.; Gyarmathy, V.A.; Miller, M. ; Frajzyngier, V. ; Zhao, M. ; Frieman, S.R. ; Des Jarlais, D.C. Injecting and sexual risk correlates of HBV and HCV seroprevalence among new drug injectors. Drug Alcohol Depend., 2007, 89, 234.

[34] Hoffmann, G.; Berglund, G.; Elmståhl, S.; Eriksson, S.; Verbaan, H. Widell, A.; Lindgren, S. Prevalence and clinical spectrum of chronic viral hepatitis in a middle-aged Swedish general urban population. Scand. J. Gastroenterol., 2000,35, 861 .

[35] Scheinmann, R.; Hagan, H.; Lelutiu-Weinberger, C.; Stern, R.; Des Jarlais, D.C.; Flom, P.L.; Strauss, S. Non-injection drug use and Hepatitis C Virus: a systematic review. Drug Alcohol Depend., 2007, 89, 1.

[36] Tortu, S.; McMahon, J.M.; Pouget, E.R.; Hamid, R. Sharing of noninjection drug-use implements as a risk factor for hepatitis C. Subst. Use Misuse, 2004, 39, 211.

[37] Howe, C.J.; Fuller, C.M.; Ompad, D.C.; Galea, S.; Koblin, B.; Thomas, D.; Vlahov, D. Association of sex, hygiene and drug equipment sharing with hepatitis $\mathrm{C}$ virus infection among non-injecting drug users in New York City. Drug Alcohol Depend., 2005, 79, 389.

[38] Quaglio, G.; Pajusco, B.; Civitelli, P.; Migliozzi, S.; Des Jarlais, D.C.; Romanò, L.; Lechi, A.; Mezzelani, P.; Lugoboni, F. Immunogenicity, reactogenicity and adherence with hepatitis A vaccination among drug users. Drug Alcohol Depend., 2004, 74, 85. 